\title{
Emotional Intelligence and Gender Differences in the Adolescent Children of Employed Mothers and Homemakers
}

\author{
Batul H. Sukhsarwala 1 , Dr. Arefa J. Mansuri 2
}

\begin{abstract}
ABATRACT
The present study assessed the impact of maternal employment on the emotional intelligence of the adolescents. The sample consisted of 69 adolescents of employed mothers including 35 girls and 34 boys and 74 adolescents of homemakers including 41 girls and 33 boys. Total sample size was 143 adolescents of Ahmedabad City, studying in 8th and 9th standard. The Emotional Intelligence Scale translated into Gujarati by Dr. Pallavi Patel and Dr. Hitesh Patel was used to collect data. The data was analyzed using ' $t$ ' test. The result revealed that the adolescent children of employed mothers had high emotional intelligence. The female children of employed mothers showed more emotional intelligence, while there were no gender differences in the emotional intelligence of adolescent children of homemakers.
\end{abstract}

Keywords: Adolescents, Emotional Intelligence, Maternal Employment, Gender Differences

\section{INTRODUCTION:}

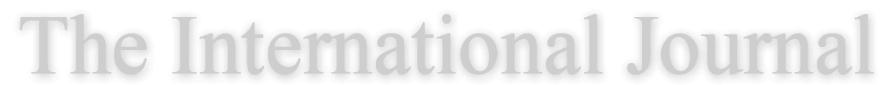

Adolescence is one of the important periods of life. It is characterized by innumerable and unique problems. With the demands of globalization, the nature and number of challenges have become still more compared to the yesteryears. Family, which plays an important role in the personality development of adolescents, is undergoing structural, emotional and interactional transformations. The contributions of mothers in shaping the personality of their children cannot be ignored. But an unprecedented number of women, especially mothers are entering the labor force either due to economic necessity or in search of identity. This has led to radical shift in the traditional role of mother as a 'care taker' to a 'bread earner' and has altered child rearing goals and practices. Hence, an attempt is made to see the effects of it on emotional intelligence of children.

${ }^{1}$ Student, M.Sc. Neuropsychology, Institute of Behavioral Sciences, Gujarat Forensic Science University, Gandhinagar, Gujarat, India.

2 Associate Professor, Dept. of Psychology, St. Xavier's College, Gujarat University, Ahmedabad, India. 


\section{Emotional Intelligence and Gender Differences in the Adolescent Children of Employed Mothers and Homemakers}

\section{Emotional Intelligence:}

In the last ten years, the concept of emotional intelligence has aroused much interest in society and in academia. Emotional Intelligence is the ability or tendency to perceive, understand, regulate and harness emotions adoptively in self and others. (Schutte, et al., 1998). Research is confirming the relation between emotional intelligence and some positive developmental outcomes such as: subjective well-being (Gallagher \& Vella-Brodrick, 2008), adaptive coping styles and mental health (Mavroveli, Petrides, Reiffe, \& Baker,2007), mental ability and positive personality traits (Van Rooy \& Viswesvaran, 2004), academic achievement (Schute, Malouff, Hall, Haggerty, Cooper, Golden, \& Dornheim, 1998), school adjustment (Adeyemo, 2005), and physical and psychological health (Tsaousis \& Nikolaou,2005).

Several factors affect the development of emotional intelligence in children. Child's character, neurophysiology and cognitive enhancement are the important factors (Eisenberg \& Morris, 2002; Goldsmith \& Davidson, 2004). However it has been seen that emotional intelligence may strengthen or dull with the effect of both these factors and social relationships like family and circle of friends. Family environment is especially the most important one among these (Cole, Martin, \& Denis, 2004; Parke, 1994; Walden \& Smith, 1997).

Family environment affects children's emotional intelligence in three aspects. Firstly children learn emotions by observing the people around them. Secondly their experiences and behaviors related to parent's emotions ensure children to become appropriate to society's expectations. Thirdly factors reflecting the emotional status of family such as the quality of emotional attachment between the child and the parents, attitude of parents, emotional and social openness, and marital relationship have impacts on emotional intelligence (Morris et al. 2007).

\section{Maternal Influence and Emotional Intelligence of Children:}

With the cutting of the umbilical cord, physical attachment to our mothers ends and emotional and psychological attachment begins. While the first attachment provides everything we need to thrive inside the womb, many psychologists believe the second attachment provides the psychological foundation and maybe even the social and physical buffer we need to thrive in the world. There is an influence of mothers' nature, personality, competencies etc. on the child. The child develops intellectual and emotional traits by getting influenced by her mother.

Evidence comes from Eisenberg and Fabes (1994) who found a link between mothers' perceptions of their children's temperament and mothers' reactions to their children's negative emotions. In another study, mothers' perceptions of girls' negative emotionality were positively associated with mothers who were minimizing their children's negative emotion, and were negatively associated with reports of helping to solve the issue that resulted in the negative emotion (Eisenberg, Fabes, \& Murphy, 1997).

Gottman, Fainsilber-Katz, and Hooven (1997) have recently proposed that parental metaemotion philosophy represents an important component of how children's emotions are socialized. Meta-emotion philosophy can be conceptualized as an emotional understanding between parents and children, and can theoretically be understood as an 'organized set of feelings and cognitions regarding one's own emotions and the emotions of others' (Gottman et al., 1997, p. 7). 


\section{Emotional Intelligence and Gender Differences in the Adolescent Children of Employed Mothers and Homemakers}

\section{Maternal Employment and Emotional Intelligence:}

Sociologists, social psychologists and Educationists got interested in the field of children of working and non-working mothers to find out the problems that the children of working mothers face. Various studies have been conducted to see the effect of maternal employment on personal and social traits of children. Hoffman (1963) found that the children of working mothers appeared to be less assertive and less affective in their peer interaction. These children helped someone less in house hold tasks than did the children of non-working mothers. Moore's (1963) data indicate that the children who had been left by their mothers from early infancy showed more dependent attachment to their parents than did any other children. They exhibited other symptoms of insecurity such as nail biting and bad dreams. Miller (1975) reveals that daughters of working mothers were found to be more aggressive and less passive than daughters of nonworking mothers. Ribble (1979) has found that children who were not fortunate enough to have the loving, caring and constancy of their mother during their earlier years reacted with negativism, hypertension, stupors sleep, diarrhea and emotional imbalance.

According to Hoffman (1980), fulltime employment may result in less effective socialization of sons because their more active behavior requires greater parental monitoring and intervention than is necessary for girls. Bronfenbrenner, Henderson (1984) and Alvarez (1985) have found that highly educated full time employed mothers described their three year old sons in especially negative terms. Their boys seemed demanding and non-compliant. Rane (1986) found that neurotic disorders were located in the children of working mothers. Sharma (1986) has revealed that the children of non- working mothers were found to be more excited, tender hearted, sensitive, dependent and more protective. Mody and Murthy (1988) have revealed that the children of employed mothers were found to be careless and slightly emotionally unstable in the early years compared to the children of nonemployed mothers. Vandell \& Ramanan (1991) have found that children with latch key experience have more behaviour problems. They are emotionally weak.

Sroufe et al (1993) have found that insecurely attached infants by contrast, often have later problems: inhibitions and negative emotions in toddler hood, hostility towards other and dependency during the school years. Walzer (1996) has revealed that working mothers are more likely to think about their babies and to feel guilty if they become so consumed with the demands of their jobs that they fail to think about their babies. Andrabi (1997) found that the children of working women experience more emotional adjustment problems. Hill and others (2001) found that when a child's mother works in the first year of life it can have a negative effect on the child's later development. Koschanska (2001) has found that insecurely attached toddlers show more negative emotions (fear, distress and anger) while securely attached children show more joyfulness, even in the same situation. Brooks - Gunn, Han and Waldfogel (2002) in their longitudinal study found that the three year old children of mothers who went to work before the children were nine months old had poorer cognitive outcomes than three year old children who had stayed at home with their mothers in the first nine months of the child's life.

Vijayalaxmi \& Bowlby (2007) have found that the adolescent children of home makers have significantly higher self concept. The children of home makers have significantly higher self concept and higher achievement motivation than the children of employed mothers. The female 
children of home makers are having significantly higher emotional maturity compared to the male children of home makers. The children of employed mothers are more socially maladjusted and lacked independence to a very highly significant level compared to the children of home makers. Hock, McBride \& Gnezda (2004) have revealed that there existed a positive relation between maternal separation anxiety and children's anxieties and separation from their mothers. This is perceived as a threat to the child's well being and/or to her own psychological equilibrium. Such anxiety may be reflected in feelings of worry, sadness, or guilt.

Most researchers have focused their attention on elementary school aged children, because of the widely held belief that adolescents need less contact with their mothers than do the younger children who might at a risk for a variety of psychological problems as a result of repeated separations from their mother (Bowlby,1973). This view may not be warranted, however, since adolescents continue to interact with their mothers and alterations of the family system as a result of maternal employment might have a profound effect on adolescent development (Montemayor \& Clayton, 2001). On the positive side, adolescents with working mothers may develop a greater degree of autonomy and adult maturity than those with nonworking mothers. Employed mothers may have a less stressful relationship with their adolescent children because they would not be as fully invested in childrearing and so could more easily relinquish maternal control than the fulltime homemakers (Birnbaum,1975).

With such varied results over a period of time, an attempt is made by the investigator to find the effect of maternal employment on emotional intelligence of adolescents and the gender differences in the adolescent of the employed mothers and homemakers.

\section{OBJECTIVES:}

The following objectives were formulated:

1) To identify the adolescent children of the employed mothers and homemakers.

2) To study emotional intelligence of the adolescent children of employed mothers and homemakers.

3) To study the gender differences in the emotional intelligence of the adolescent children of employed mothers and homemakers.

\section{NULL HYPOTHESES:}

The following hypotheses were framed:

1) There is no significant difference in the mean scores of emotional intelligence of the adolescent children of employed mothers or homemakers (Composite score).

2) There is no significant difference in the mean scores of emotional intelligence of the adolescent children of employed mothers or homemakers (Factor wise).

3) There is no significant difference in the mean scores of emotional intelligence of the adolescent girls or boys of employed mothers (Composite score).

4) There is no significant difference in the mean scores of emotional intelligence of the adolescent girls or boys of home makers (Composite score). 


\section{METHOD:}

\section{Sample:}

For this study, total sample size of 143 adolescents of Ahmedabad City, studying in $8^{\text {th }}$ and $9^{\text {th }}$ standard were included. The sample consisted of 69 adolescents of employed mothers including 35 girls and 34 boys and 74 adolescents of homemakers including 41 girls and 33 boys.

\section{Tools:}

(a) The personal data sheet was prepared to collect the information regarding student's age, standard (class), sex, income-status, number of children in the family, their mother's qualification, employment etc.

(b) The Emotional Intelligence Scale: This scale is translated into Gujarati by Dr. Pallavi Patel and Dr. Hitesh Patel was used to measure the EI of adolescents. The scale consisted of 77 statements where the respondents had to tick mark in one of the four alternatives provided. This scale consisted both positive and negative statements which were calculated as per the manual.

\section{Procedure:}

For the data collection two schools of Ahmedabad city were approached. The permission of the principal and the teachers was taken and then the high school students were approached personally. A rapport was built with them and then the above mentioned test along with the personal data sheet was given. The sample consisted of 143 students in $8^{\text {th }}$ and $9^{\text {th }}$ grade. The data collected was being analyzed based on four components of emotional intelligence scale and the details regarding maternal employment derived from personal data sheet. ' $t$ ' test was the statistical technique used to analyze the data.

\section{RESULTS:}

Table 1: Showing the Mean, SD and " $t$ " of emotional intelligence and its factors of the adolescent children of Employed mothers and Homemakers.

\begin{tabular}{|c|c|c|c|c|c|c|c|c|}
\hline & \multicolumn{3}{|c|}{ Employed Mothers } & \multicolumn{3}{|c|}{ Home Makers } & \multirow[t]{2}{*}{ "tt" } & \multirow[t]{2}{*}{ Significance } \\
\hline & $\mathbf{N}$ & Mean & SD & $\mathbf{N}$ & Mean & SD & & \\
\hline $\begin{array}{l}\text { Emotional } \\
\text { Intelligence }\end{array}$ & 69 & 240.18 & 15.85 & 74 & 227.05 & 15.67 & 2.06 & 0.05 \\
\hline \multicolumn{9}{|l|}{ Factors of EI } \\
\hline Self Awareness & 69 & 118.92 & 10.40 & 74 & 111.21 & 12.34 & 3.05 & 0.01 \\
\hline Self management & 69 & 64.32 & 6.70 & 74 & 64.364 & 15.05 & 0.98 & $\begin{array}{c}\text { Not } \\
\text { significant }\end{array}$ \\
\hline Social awareness & 69 & 29.5 & 5.61 & 74 & 25.95 & 4.28 & 1.98 & 0.05 \\
\hline Social skills & 69 & 34.59 & 6.85 & 74 & 34.33 & 6.38 & 0.81 & $\begin{array}{c}\text { Not } \\
\text { significant }\end{array}$ \\
\hline
\end{tabular}

Table 1 shows the mean, SD and t of emotional intelligence and its factors of the adolescent children of employed mothers and homemakers. The difference between the emotional 
intelligence of the adolescent children of employed mothers and homemakers was found to be significant at $0.05(\mathrm{t}=2.06)$. It means that the emotional intelligence of adolescent children of employed mothers is more than those of the homemakers. Hence, the null hypothesis is rejected. The Self-awareness of the adolescent children of employed mothers is higher than their counterparts. The null hypothesis is rejected at 0.01 level $(t=3.05)$. Similarly, the social awareness of the adolescent children of employed mothers is significantly high at 0.05 level $(\mathrm{t}=1.98)$. The probable reason would be that the dual role of the employed mother as a professional and a care taker would help the child in developing an insight and ability to cope with the situations independently than the constant helping homemakers. Moreover, the children would be able to make decisions, discuss emotions and will be able to communicate clearly and directly (Mahmood, Hassan 2012). The social awareness would be more as the adolescent children of employed mother would see their mothers interacting with outside and adopt such attitude easily than their counterparts. Moreover, they would be aware of the importance of the role of physical appearance and attributes in social acceptance and success as they are exposed to a wider world apart from home and school because of maternal employment (Hangal and Vijyalaxmi 2007).

However, it should be noted that there is no significant difference in the self-management scores of the adolescent children. The probable reason would be that adolescents today are career oriented and hence they are able to develop skills like adaptability and self-control from the outside world. Similarly, the social skills are not affected by maternal employment as the child interacts with many people at school, coaching, on social networking sites and is not merely bound to interact with the family.

Table 2: Showing the Mean, SD and " $t$ " of emotional intelligence and its factors of the adolescent Girls and Boys of Employed mothers.

\begin{tabular}{|c|c|c|c|c|c|c|c|c|}
\hline & \multicolumn{3}{|c|}{ Girls } & \multicolumn{3}{c|}{ Boys } & "t” & Significance \\
\hline & N & Mean & SD & N & Mean & SD & & \\
\hline $\begin{array}{c}\text { Emotional } \\
\text { Intelligence }\end{array}$ & 35 & 243.38 & 16.78 & 34 & 228.91 & 18.21 & 3.12 & 0.01 \\
\hline
\end{tabular}

Table 2 shows the mean, SD and $t$ of the emotional intelligence of adolescent girls and boys of employed mothers. The mean of emotional intelligence of girls is more than the boys. Hence, the null hypothesis is rejected at 0.01 level $(\mathrm{t}=3.12)$. The probable reason could be that the girls would take up few responsibilities in the absence of the mother during the day unlike boys. Also the girl would learn to take care of the house and try to play dual roles like her mother. 
Table 3: Showing the Mean, SD and " $t$ " of emotional intelligence and its factors of the adolescent Girls and Boys of Homemakers.

\begin{tabular}{|c|c|c|c|c|c|c|c|c|}
\hline & \multicolumn{3}{|c|}{ Girls } & \multicolumn{3}{c|}{ Boys } & “t”' & Significance \\
\hline & N & Mean & SD & N & Mean & SD & & \\
\hline $\begin{array}{c}\text { Emotional } \\
\text { Intelligence }\end{array}$ & 41 & 243 & 15.11 & 33 & 242.75 & 16.59 & 0.95 & $\begin{array}{c}\text { Not } \\
\text { significant }\end{array}$ \\
\hline
\end{tabular}

Table 3 shows the mean, SD and t of the emotional intelligence of adolescent girls and boys of homemakers. There is no significant difference in the mean of the emotional intelligence of girls and boys of Homemakers. Hence the null hypothesis is accepted. The probable reason would be the same kind of constant attention and care by the homemakers to both the genders.

\section{CONCLUSION:}

1) It has been found that the emotional intelligence of the adolescent children of employed mothers and homemakers is significantly different on composite score. The emotional intelligence of the adolescent children of employed mothers is more than their counterparts.

2) The study has revealed a significant difference in the self awareness of the adolescent children of employed mothers and homemakers. The children of employed mothers showed signs of intelligence and ability to cope with the challenges.

3) The study showed that there is no significant difference in the self management score of children as they develop skills like adaptability and self-control from the outside world.

4) The study revealed significant difference in the social awareness of the adolescent children of employed mothers and homemakers. The adolescent children of employed mothers showed more organizational awareness and empathy than their counterparts.

5) It has also been found that there is no significant difference in the social skills of adolescent children of employed mothers or homemakers as children develop communication skills and leadership qualities while interacting with the outside world.

6) There were gender differences in the composite score of emotional intelligence of the employed mothers. The emotional intelligence of girls was more than the boys as they adapt a sense of responsibility easily.

7) There were no gender differences in the composite score of emotional intelligence of homemakers. The probable reason would be the same kind of care from the mother.

\section{SUGGESTIONS:}

1) There is a need for training in management of emotions among adolescents.

2) The mothers need to sensitize towards the need of their children.

3) The homemakers need to take more measures for their children's development.

4) Mothers also need guidance and counseling in bringing up their male and female children effectively with the egalitarian attitude.

5) Research is required on large samples measuring the development (physical, social and emotional) of adolescent children of employed mothers and homemakers. 


\section{REFERENCES:}

1. Alvarez, W. F. 1986. The meaning of maternal employment for mothers and their perceptions of their three year old children, Developmental Psychology 56, pp 350-360.

2. Andrabi, G. A. 1997. A comparative study of children of working and non working women in respect of their adjustment, academic achievement and socio-economic status. Unpublished M.Phil Dissertation Univ. of Kashmir.

3. Hangal S.A.A Vijyalaxmi. 2007. Self concept, emotional maturity and achievement motivation of the adolescent children of employed mothers and home makers. Journal of the Indian Academy of Applied Psychology 33, 103-100 Karnatak University, Dharwad.

4. Hock, E; McBride, S; \& Gnezda, M. 2004. Maternal separation anxiety: mother-mother infant separation from the maternal perspective. Child development, 60, 793-802.

5. Hoffman L. W. 1963. "The decision to work" In Nye F. Ivan \& Hoffman LW (ed). The employed mothers in America, Chicago: Rand McNally \& Company.

6. Hurlock E. B. 2007. Child Development. Tata McGraw Hill Publishing Company Ltd. New Delhi.

7. Khan Mahmood \& Hassan Asma (2012) Emotional Intelligence of Children of Working and Non-working Mothers, (University of Kashmir) http: www.sciencepub.net/researcher.

8. Mahajan, A. 1966. Women's two roles: a study of role conflict, Indian Journal of Social Work, 24 (4), pp 377-380.

9. Miller, S. M. 1975. Effect of Maternal Employment on sex role of perception interests and self-esteem in kindergarten Girls. Development Psychology, II.

10. Mody, S.N; and Murthy, V.N. 1988. The study of mental health of children of working mothers. Journal of personality and clinical studies, 4, 161-164.

11. Montemayor Raymond and Clayton Mark (2001) Maternal Employment and Adolescent Development. (University of Utah)

12. Patel Pallavi and Hitesh: "Emotional Intelligence scale" Indian Adaptation Manual

13. Ramu, G.N. 1989. Women, work and marriage in urban India- a study of dual and single earner couples, New Delhi- Sage Publications.

14. Rane, S. A. 1986. An investigation into self improvement programme of working mothers in greater Bombay with a view to examine psychological problems in society. Ph.D., Education Bombay University.

15. Ribble . 1979. Psychology of adolescence, Engle Wood Cliffs, Prentice Hall.

16. Sharma, R. 1986. A comparative study of the children of working and non-working mothers. Ph. D Education, M. Sukh University.

17. Sroufe L. A. 1993. Emotional development: the organisation of emotional life in the early years. New York: Cambridge Uni. Press. pp 315 - 342

18. Zhou, Q., Eisenberg, N., Lasoya, S.H., Fabes, R.A., Reiser, M., Guthrie, I.K., et al. (2002, May/June). The relations of parental warmth and positive expressiveness to children's empathy-related responding and social functioning: a longitudinal study. Child Development, 73 (3), 893-915. 